\title{
Oncogene ERB B
}

National Cancer Institute

\section{Source}

National Cancer Institute. Oncogene ERB B. NCI Thesaurus. Code C17763.

ERBB DNA sequences are related to certain avian erythroblastosis virus sequences. The cellular genes encode members of the epidermal growth factor receptor (EGFR) family (ERBB1, 2, 3, and 4). The 110-kb EGFR gene locus encodes the EGF receptor, a cell surface transmembrane protein tyrosine kinase involved in regulation of cell growth and differentiation. ERBB2, ERBB3, and ERBB4 genes encode heregulin/neuregulin receptor tyrosine kinase homo- and heterodimers important in the control of cell proliferation and in the pathogenesis of human cancers. ERBB proteins are over expressed in a significant portion of adenocarcinomas at various sites, especially in the breast; gene amplification appears to be the predominant cause of over expression. Oncogene ERBB2 encodes tumor antigen p185. The human ERBB1 gene is located at 7p12.3-p12.1, ERBB2 is located at 17p12-21, ERBB3 is located at 12q13, ERBB4 is located at 2q33.3-q34. 